\title{
Hyperglycaemic crisis in the Eastern Cape province of South Africa: High mortality and association of hyperosmolar ketoacidosis with a new diagnosis of diabetes
}

\author{
C O Ekpebegh, B Longo-Mbenza, A Akinrinmade, E Blanco-Blanco, M Badri, N S Levitt
}

Objectives. To describe the frequencies, presenting characteristics (demographic, clinical and biochemical) and outcomes (duration of admission and mortality rates) for various types of hyperglycaemic crisis.

Methods. Retrospective review of medical records of patients with hyperglycaemic crisis admitted to Nelson Mandela Academic Hospital, Mthatha, E Cape, from 1 January 2008 to 31 December 2009. Outcome measures were duration of admission and mortality.

Results. Data were available for 269 admissions (response rate $81.0 \%), 169$ females and 100 males. Admissions for hyperglycaemia (HG, N=119), and non-hyperosmolar diabetic ketoacidosis (NHDKA, $N=97$ ) were more frequent than those for hyperosmolar hyperglycaemic state (HHS, N=29) and hyperosmolar diabetic ketoacidosis (HDKA, $N=24$ ). Duration of admission was similar in all groups. Mortality was high in all groups, but was higher in patients with HDKA (37.5\%, risk ratio (RR) 3.88, 95\% confidence interval (CI) $1.41-10.67, p=0.009)$, HHS (31.0\%, RR 2.91, 95\% CI $1.09-7.75, p=0.033)$ and HG (19.5\%, RR 1.56, 95\% CI $0.75-3.21$, $p=0.236)$ than in those with NHDKA (13.4\%). HDKA (62.5\%) was associated with new-onset diabetes more often than NHDKA (27.8\%), HHS $(44.8 \%)$ or HG $(17.6 \%)(p<0.0001)$. An altered level of consciousness was more frequent in HDKA than NHDKA admissions (RR 5.71, 95\% CI 1.90 - 17.17, $p=0.002$ ).

Conclusions. Duration of hospital stay was similar across groups. Mortality rates were high in all groups. New-onset diabetes, altered level of consciousness and mortality were more characteristically associated with HDKA than any of the other types of hyperglycaemic crisis. Optimal glycaemic control in known diabetic patients will reduce rates of hyperglycaemic crisis admissions.

S Afr Med J 2010; 100: 822-826.
Diabetic hyperglycaemic crisis is a major reason for high-care unit admissions, ${ }^{1}$ with mortality rates of up to $30 \%{ }^{2-9}$ It is characteristically classified as ketoacidotic or hyperosmolar. ${ }^{10}$ Presentations with the combination of ketoacidosis and hyperosmolality are recognised, ${ }^{6,7,11-16}$ and have variably been described as ketoacidosis with hyperosmolality or hyperosmolar state with ketoacidosis, depending on whether ketoacidosis or hyperosmolality was considered dominant. ${ }^{15}$

Therapy and outcome of treatment for hyperglycaemic crisis is related to the presence of hyperosmolality and ketoacidosis. ${ }^{1}$ Hyperosmolality is associated with the use of hypotonic fluids, anticoagulation and the more frequent occurrence of vascular thrombosis, ${ }^{17}$ while ketoacidosis may necessitate the use of sodium bicarbonate. $^{18}$

Hyperglycaemic hyperosmolar non-ketoacidosis is associated with a higher morbidity and mortality than diabetic ketoacidosis, ${ }^{6,719}$

Department of Internal Medicine, Walter Sisulu University, Mthatha, E Cape C O Ekpebegh, FMCP

B Longo-Mbenza, DSc

Department of Internal Medicine, Nelson Mandela Academic Hospital, Mthatha A Akinrinmade, MB BS

Department of Chemical Pathology, Walter Sisulu University

E Blanco-Blanco, MD

Department of Medicine, University of Cape Town

M Badri, MSc (Med), PhD

Division of Diabetic Medicine and Endocrinology, Department of Medicine, University of Cape Town

N S Levitt, MB ChB, MD, FCP (SA) which is mainly attributed to hyperosmolality, older age $e^{6,7}$ and the more frequent association of hyperosmolar non-ketoacidosis with type 2 diabetes. ${ }^{19}$ Few studies ${ }^{6,711,13}$ have described the clinical and laboratory features and outcomes of treatment for hyperosmolar diabetic ketoacidosis. A single report from Africa ${ }^{11}$ included only 8 cases.

This study investigated the frequencies, presenting characteristics and outcomes of admissions for various types of hyperglycaemic crisis at Nelson Mandela Academic Hospital, Walter Sisulu University (WSU), Mthatha. The hospital is the referral centre for primary and secondary health care facilities in the O R Tambo district of the Eastern Cape province of South Africa, which has a population of about 1.7 million people. ${ }^{20}$ Like the rest of the province the $\mathrm{O}$ R Tambo district has poorly developed health infrastructure and a disproportionately high burden of communicable diseases, particularly HIV/AIDS, tuberculosis and neurocysticercosis.

\section{Methods}

A retrospective review of hospital records of patients with hyperglycaemic crisis admitted to the medical department of Nelson Mandela Academic Hospital from 1 January 2008 to 31 December 2009 was performed. Hyperglycaemic crisis referred to admissions in which insulin infusion and intravenous fluid rehydration were initiated. Data from the records were socio-demographic information, diabetes type, precipitating cause for hyperglycaemic crisis, serum biochemical measurements at presentation, duration of admission and in-hospital deaths. The study was approved by the Ethics Committee of WSU.

Admissions were categorised as follows: $(i)$ non-hyperosmolar diabetic ketoacidosis (NHDKA); (ii) hyperosmolar diabetic ketoacidosis (HDKA); (iii) hyperosmolar hyperglycaemic state (HHS); and (iv) hyperglycaemia (HG). Definitions used were: NHDKA - blood glucose $>13.9 \mathrm{mmol} / \mathrm{l}$, ketosis, serum bicarbonate $<18 \mathrm{mmol} / \mathrm{l}$ and calculated effective serum osmolality $\leq 320 \mathrm{mosmol} /$ $\mathrm{kg}$; HDKA - blood glucose $>13.9 \mathrm{mmol} / \mathrm{l}$, ketosis, serum bicarbonate 
$<18 \mathrm{mmol} / \mathrm{l}$, and calculated effective serum osmolality $>320 \mathrm{mosm} /$ $\mathrm{kg}$; HHS - blood glucose $>33.3 \mathrm{mmol} / \mathrm{l}$, serum bicarbonate $\geq 18$ $\mathrm{mmol} / \mathrm{l}$, and calculated effective serum osmolality $>320 \mathrm{mosm} /$ $\mathrm{kg}$; and HG - blood glucose $>13.9 \mathrm{mmol} / \mathrm{l}$, serum bicarbonate $\geq 18$ $\mathrm{mmol} / \mathrm{l}$, and calculated effective serum osmolality $\leq 320 \mathrm{mosm} / \mathrm{kg}$. Ketosis referred to at least $1+$ ketonuria on dipstick urinalysis or trace ketonaemia on qualitative laboratory serum analysis. Acidosis and severe acidosis were diagnosed on the basis of serum bicarbonate levels of $<18 \mathrm{mmol} / \mathrm{l}$ and $<10 \mathrm{mmol} / \mathrm{l}$, respectively. Ketoacidosis referred to ketosis with serum bicarbonate level $<18 \mathrm{mmol} / \mathrm{l}$. Effective osmolality was calculated as: [2(serum sodium in $\mathrm{mmol} / \mathrm{l})+$ plasma glucose in mmol/l]. Type of diabetes (type 1 and type 2) was based on the diagnosis before the index hyperglycaemic crisis. New diabetes referred to patients without a previous diagnosis of diabetes. Impaired level of consciousness was defined as a Glasgow Coma Scale $<15$, hypernatraemia as uncorrected serum sodium $>150 \mathrm{mmol} / \mathrm{l}$, hypokalaemia as serum potassium $<3.5 \mathrm{mmol} / \mathrm{l}$, hyperkalaemia as serum potassium $>5.5 \mathrm{mmol} / \mathrm{l}$, hypochloraemia as serum chloride $<94 \mathrm{mmol} / \mathrm{l}$, and hyperchloraemia as serum chloride $>104 \mathrm{~mol} / \mathrm{l}$. Precipitating factors for hyperglycaemic crisis refer to factors including co-morbidities that are associated with deterioration in glycaemic levels.

Treatment consisted of intravenous fluids and insulin administered according to standard protocols. ${ }^{10}$ Blood glucose levels were monitored hourly and dipstick urinalysis for ketones done 4-hourly, while serum electrolytes, urea and creatinine were measured once daily. Potassium replacement as $20 \mathrm{mmol}$ of potassium chloride was added to each litre of rehydration fluid, after hyperkalaemia had been excluded. Use of anticoagulation in patients with hyperosmolality and sodium bicarbonate therapy in severe acidosis was rare.

\section{Statistical analysis}

Data were presented as the median (interquartile range) for continuous variables and proportions (\%) with (number of admissions) for discrete variables. The non-parametric Kruskal-Wallis one-way ANOVA was used to compare continuous variables between the four types of hyperglycaemic crisis, with post-hoc comparisons of mean ranks of all pairs of groups. Proportions between two groups were compared using Pearson's chi-square test. Proportions across all groups were compared using Pearson's chi-square test with a Bonferroni adjustment. All tests were two-sided and a $p$-value $<0.05$ was considered significant. Logistic regression models were fitted to compare risk of mortality, altered level of consciousness and onset of new diabetes between the four types of hyperglycaemic crisis. Risk was expressed as risk ratio (RR), using the NHDKA as the baseline risk group. Data were captured on a customised MS Excel spread sheet and analysed using SPSS version 15 (SPSS, Inc, Chicago, IL, USA) and Statistica version 9 (StatSoft, Tulsa, Oklahoma, USA).

\section{Results}

There were 764 diabetes-related admissions to the medical wards during the study; 332 were for DKA, HHS and HG. Complete data on key variables such as age, gender, type of diabetes, blood glucose, serum sodium, serum bicarbonate, ketosis and duration of admission (Table I) were available for 269 admissions, 169 females and 100 males (response rate $81 \%)$. They comprised 119 HG (44.2\%), 97 NHDKA (36.1\%), 29 HHS (10.8\%) and 24 HDKA (8.9\%). Ten patients admitted 2 - 7 times accounted for a total of 33 admissions (Table II). There were readmissions for NHDKA, HDKA and HG but not for HHS. The HHS group included 6 admissions with blood glucose levels below $33.3 \mathrm{mmol} / \mathrm{l}$. Seven admissions with blood glucose levels below $13.9 \mathrm{mmol} / \mathrm{l}$ were observed, 4 for NHDKA, 1 for HDKA and 2 for HG; this was attributed to initial treatment at the referring health facilities, which typically took the form of normal saline infusion and 10 units intravenous bolus of soluble insulin. The 63 admissions for which records were not available had the following diagnoses: DKA $(N=11)$, HHS $(N=5)$ and HG $(N=47)$.

The mean ages in the two DKA groups were similar, and significantly lower than in the HHS and HG groups (Table I). No person with HHS was younger than 40 years or had type 1 diabetes, in contrast to other groups. Females dominated all groups except the HHS group, which had a majority of males.

Precipitating factors were identified in $36.1-44.8 \%$ of admissions across the four groups. The predominant factors were infections $(N=62)$, cerebrovascular disease $(N=17)$ and poor drug compliance $(N=11)$. Of the 17 cases of cerebrovascular disease, 12 were in the HG group, 3 in the HHS group, 2 in the HDKA group and none in the NHDKA group. One of the 10 patients who died had type 1 diabetes and died during her 7 th admission. The median durations of hospitalisation were comparable in all groups.

The four groups had equally high glycated haemoglobin (HbA1c) levels at admission (Table III): $1.6 \%$ of NHDKA, $0 \%$ of HDKA, $0 \%$ of HHS and $1.3 \%$ of HG patients had an HbAlc $<7 \%$ at admission. Hypernatraemia and hyperchloraemia were more prevalent in the HDKA group than in the other groups. Hypochloraemia was the dominant serum chloride abnormality in NHDKA. Acidosis was documented in all groups. The proportions of admissions with severe acidosis were comparably high in both ketoacidotic groups; 97 (53.6\%) in NHDKA versus 24 (54.2\%) in HDKA.

Mortality was high in all groups (Table I), and was significantly higher in patients with HDKA (RR 3.88, 95\% confidence interval (CI) $1.41-10.67, p=0.009$ ), HHS (RR 2.91, 95\% CI $1.09-7.75, p=0.033$ ) and HG (RR 1.56, 95\% CI $0.75-3.21, p=0.236$ ) than in those with NHDKA (Table IV).

There were similar proportions of patients with type 1, type 2 and new diabetes in the NHDKA group, while the vast majority of HDKA admissions were patients with new diabetes (Table I). Taking the NHDKA group as a baseline risk group, patients with HDKA and HHS had a significantly higher risk of new diabetes (Table IV).

An altered level of consciousness was commonest in the HDKA group, followed by HHS, NHDKA and lastly HG. The rates of altered level of consciousness were similarly high in the HDKA and HHS groups $(p=0.714$, but higher in both hyperosmolar groups than in the NHDKA and HG groups $(p=0.001$ for HDKA v. NHDKA, $p=0.007$ for HHS v. NHDKA, and $p=0.000$ for HDKA v. HG and HHS v. HG, respectively). The NHDKA and HG groups had similar rates of altered level of consciousness $(p=0.146)$. Similar to the above analyses, patients with HDKA and HHS had a significantly higher risk of altered level of consciousness.

\section{Discussion}

This study found unacceptably high mortality rates across all groups, higher representation of newly diagnosed diabetes in the HDKA group than in the other groups, and markedly elevated admission $\mathrm{HbA}_{\mathrm{lc}}$ levels in all groups.

The overall mortality rate of $20.2 \%$ (deaths per all admissions) in the study, with a range from $13.4 \%$ for NHDKA to $37.5 \%$ for HDKA, is higher than the rates of $2.7-7.7 \%$ for NHDKA and $0-9.6 \%$ for HDKA from centres ${ }^{6,711}$ that admit patients with hyperglycaemic crisis into high-care units. Patients with hyperglycaemic emergencies in Jamaica, ${ }^{13}$ also managed in the medical wards, had lower mortality rates than ours $(6.7 \%, 25 \%$ and $20.3 \%$ for NHDKA, HDKA and HHS, respectively), indicating that additional factors contribute to our high mortality rates. Although the higher mortality rate for HDKA than 
Table I. Demographic characteristics, presenting clinical characteristics and outcomes of various types of hyperglycaemic crisis

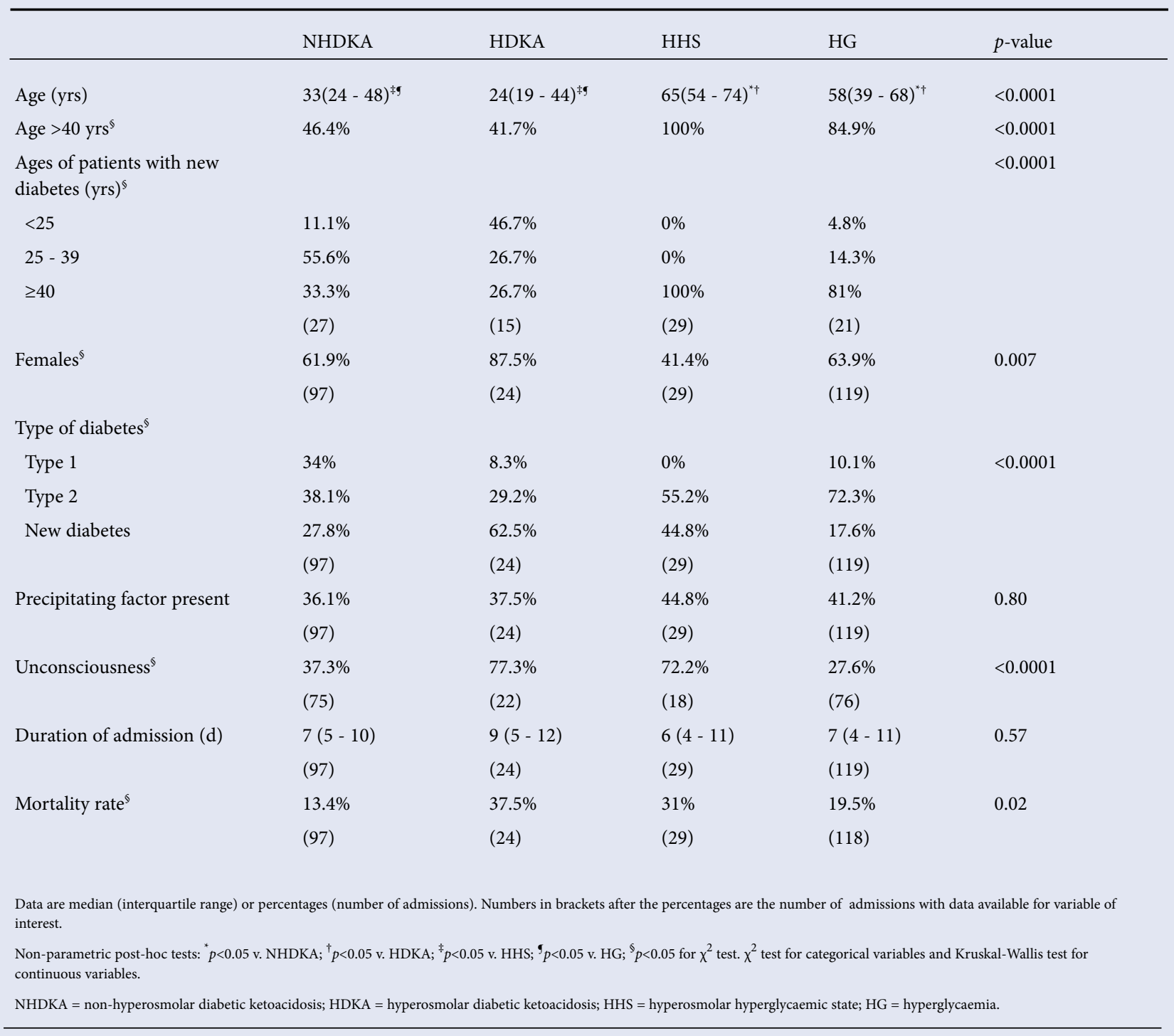

NHDKA agrees with other reports, ${ }^{6,711,13}$ the former had a similar mortality rate to HHS despite the patients being more than 20 years younger. This underscores the need to distinguish between these forms of ketoacidosis, as the combination of hyperosmolality and ketoacidosis had a worse prognosis than ketoacidosis alone despite both ketoacidotic groups being relatively young. A tendency to longer duration of admission in HDKA than NHDKA has been reported. ${ }^{11}$ We are unable to provide an explanation for our patient groups having comparable periods of hospital stay.

Admissions for HDKA, in contrast to NHDKA, were likely to be of patients with a new diagnosis of diabetes. Although hyperosmolality in HHS is explained by an age-related increase in the renal threshold for glucose and reduced sensitivity of the thirst centre, it is not clear what the underlying mechanism is in our patients with HDKA, who were relatively young $(41.7 \%$ were aged $>40$ years, compared with $100 \%$ for HHS) and had new-onset diabetes. We do not know whether they had an elevated renal threshold for glucose or an increased thirst threshold. It is also possible that as HDKA admissions were mainly of newly diagnosed diabetes subjects, who were not aware of their diabetes status, they may have presented relatively late or not taken adequate fluids to militate against ongoing renal losses (which an informed diabetic patient would have known it was necessary to do). This may explain why hypernatraemia and an altered level of consciousness were more prevalent in HDKA than NHDKA admissions. However, we have no data on the duration of symptoms or severity of polydipsia before presentation. Admissions for HHS and HG with a serum bicarbonate level below $18 \mathrm{mmol} / \mathrm{l}$ were as categorised, as ketosis was absent at presentation The factors probably contributing to low serum bicarbonate in these ketonenegative patients include uraemic and lactic acidosis, although lactate was not routinely measured in our patients.

While longitudinal studies, ${ }^{3,21,22}$ particularly in populations of black African ancestry, have shown that most patients with ketoacidosis as the first manifestation of diabetes have features of type 2 diabetes, we were unable to adequately characterise the newly diagnosed diabetic patients with NHDKA or HDKA as having type 1 or type 2 diabetes. Few patients had information on a family history of diabetes, a personal or family history of auto-immune diseases, 
Table II. Profiles of patients with repeated admissions for hyperglycaemic crisis

\begin{tabular}{|c|c|c|c|c|c|c|}
\hline Patient No. & Gender & Age (yrs) & Diabetes type & No. of admissions & $\begin{array}{l}\text { Types of } \\
\text { hyperglycaemic } \\
\text { crisis }\end{array}$ & Outcome \\
\hline 1 & $\mathrm{~F}$ & 23 & 1 & 7 & $\begin{array}{l}5 \text { times for } \\
\text { NHDKA and } 2 \\
\text { times for HG }\end{array}$ & $\begin{array}{l}\text { Died at last } \\
\text { admission }\end{array}$ \\
\hline 2 & $\mathrm{~F}$ & 51 & 2 & 3 & $\begin{array}{l}2 \text { times for HG } \\
\text { and once for } \\
\text { NHDKA }\end{array}$ & $\begin{array}{l}\text { Survived all } \\
\text { admissions }\end{array}$ \\
\hline 3 & $\mathrm{~F}$ & 51 & 2 & 2 & 2 times for HDKA & $\begin{array}{l}\text { Survived all } \\
\text { admissions }\end{array}$ \\
\hline 4 & $\mathrm{~F}$ & 16 & 1 & 4 & $\begin{array}{l}4 \text { times for } \\
\text { NHDKA }\end{array}$ & $\begin{array}{l}\text { Survived all } \\
\text { admissions }\end{array}$ \\
\hline 5 & $\mathrm{~F}$ & 69 & 2 & 3 & 3 times for $\mathrm{HG}$ & $\begin{array}{l}\text { Survived all } \\
\text { admissions }\end{array}$ \\
\hline 6 & M & 85 & 2 & 5 & $\begin{array}{l}3 \text { times for HG } \\
\text { and once each } \\
\text { for NHDKA and } \\
\text { HDKA }\end{array}$ & $\begin{array}{l}\text { Survived all } \\
\text { admissions }\end{array}$ \\
\hline 7 & $\mathrm{~F}$ & 13 & 1 & 2 & $\begin{array}{l}\text { Once each for } \\
\text { NHDKA and HG }\end{array}$ & $\begin{array}{l}\text { Survived all } \\
\text { admissions }\end{array}$ \\
\hline 8 & $\mathrm{~F}$ & 31 & 1 & 2 & $\begin{array}{l}\text { Once each for } \\
\text { NHDKA and HG }\end{array}$ & $\begin{array}{l}\text { Survived all } \\
\text { admissions }\end{array}$ \\
\hline 9 & M & 32 & 1 & 3 & $\begin{array}{l}3 \text { times for } \\
\text { NHDKA }\end{array}$ & $\begin{array}{l}\text { Survived all } \\
\text { admissions }\end{array}$ \\
\hline 10 & $\mathrm{~F}$ & 65 & 2 & 2 & 2 times for $\mathrm{HG}$ & $\begin{array}{l}\text { Survived all } \\
\text { admissions }\end{array}$ \\
\hline
\end{tabular}

weight, height, waist circumference, presence of acanthosis nigricans or C-peptide levels. Laboratory markers of islet auto-immunity were not performed as this test was not available.

The very high $\mathrm{HbA}_{1 \mathrm{c}}$ level at presentation in all groups is notable. Although admissions for HDKA were predominantly in persons newly diagnosed with diabetes, all 15 admissions for HDKA, including 8 in newly diagnosed diabetic patients for whom data on $\mathrm{HbA}_{1 \mathrm{c}}$ level were available, had $\mathrm{HbAlc}$ levels above $10 \%$. The finding that an $\mathrm{HbA}_{1 \mathrm{c}}<7 \%$ was only noted in 2 of 174 admissions (including 56 patients with newly diagnosed diabetes) with $\mathrm{HbA}_{1 c}$ levels indicates that hyperglycaemic crisis in our setting is preceded by chronic hyperglycaemia regardless of whether the patient is known to have diabetes or newly diagnosed. Indeed an elevated $\mathrm{HbA}_{1 \mathrm{c}}$ level has been reported to be associated with unprovoked ketoacidosis, and the suggested mechanism is glucotoxicity to the beta cell. ${ }^{23}$ Universal screening for diabetes is not recommended, but improving glycaemic control in our patients already diagnosed with diabetes will reduce the occurrence of hyperglycaemic crisis.

Public health measures to reduce deaths from hyperglycaemic crisis are urgently needed. This includes educating the general population on diabetes prevention through a healthy lifestyle and highlighting its common presenting symptoms. Impediments to achieving good glycaemic control in diabetic patients, particularly at referring health care facilities, must be addressed as chronic hyperglycaemia preceded most admissions for hyperglycaemic crisis. A follow-up to a study from Soweto $^{23}$ reporting high mortality in hyperglycaemic crisis described significantly reduced deaths following improved education and care of patients, particularly those who were most prone to hyperglycaemic decompensation. ${ }^{24}$
We plan to review outcomes for hyperglycaemic crisis admissions in order to assess the impact of our recently established high-care unit and accurately ascertain the type of diabetes in our new-onset diabetes patients with hyperglycaemic crisis

We acknowledge the assistance of the medical wards clerk, Miss Q Duba, in the retrieval of patient case records.

\section{References}

1. Van Zyl Smit RE, Burch VC, Willcox PA. The provision of appropriate critical care services in secondary level hospitals in South Africa. S Afr Med J 2007;97:270-272.

2. Wagner A, Risse A, Brill H, Wienahausen-Wilke V, Rothmann M, Sondern K, et al. Therapy of severe diabetic ketoacidosis (zero mortality under very-low-dose insulin application). Diabetes Care 1999;22:674-677.

3yenwe E, Loganathan R, Blum S, Ezuteh D, Erani D, Palace M, et al. Admissions for diabetic ketoacidosis in ethnic minority groups in a city hospital. Metabolism 2007;56:172-178.

Ko SH, Lee WY, Lee JH, Kwon HS, Lee JM, Kim SR, et al. Clinical characteristics of diabetic ketoacidosis in Korea over the past two decades. Diabet Med 2005;22:466-469.

. Lee HK Oh YS, Chung YH, YoO HJ Shin SH, Son HY, et al Epidemiological characteristics of ketoacidosis among Korean diabetic patients. Korean Med Sci 1987;2:7-11.

6. Metocis MacIsaac RJ, Lee LY, Mcneil KJ, Tsalmandris C, Jerums G. Influence of age on the presen
outcome of acidosis and hyperosmolar diabetic emergencies. Intern Med J 2002;32:379-385.

7. Wachtel TJ, Tetu-Mouradjian LM, Goldman DL, Ellis SE, O'Sullivan PS. Hyperosmolarity and acidosis Wachtel TJ, Tetu-Mouradjian LM, Goldman DL, Ellis SE, O'Sullivan PS. Hyperosmolarity and acidos
in diabetes mellitus; a three-year experience in Rhode Island. J Gen Intern Med 1991;6:495-502.

8. Mbugua DK, Otieno CF, Kayima JK, Amayo AA, Mcligeyo SO. Diabetic ketoacidosis: clinical presentation and precipitating factors at Kenyatta National Hospital. East Afr Med J 2005;82 (Supp 12):S191-S196.

9. Jabbar A, Farooqui K, Habib A, Islam N, Haque N, Akhter J. Clinical characteristics and outcomes of diabetic ketoacidosis in Pakistani adults with diabetes mellitus. Diabet Med 2004;21:920-923.

10. American Diabetes Association. Hyperglycaemic crisis in diabetes. Diabetes Care 2004;27(S1):S94S102.

11. Pepper DJ, Burch VC, Levitt NS, Cleary S. Hyperglycaemic emergency admissions to a secondary-level hospital - an unnecessary financial burden. S Afr Med J 2007;97:963-967.

12. Hudson O, Menon S, Kaufmann S. Combined hyperglycaemic hyperosmolar syndrome with diabetic ketoacidosis as the presentation of diabetes mellitus type 2 in an adolescent female. EndoTrends ketoacidosis as $15: 1-5$.

13. Chung ST, Perue GG, Johnson A, Younger N, Hoo CS, Pascoe RW, et al. Predictors of hyperglycaemic crisis and their associated mortality in Jamaica. Diabetes Res Clin Pract 2006;73:184-190. 
